\title{
OCENA MORFOLOGII POWIERZCHNI STOPU INCONEL 718 PO TOCZENIU WZDEUŻNYM
}

\begin{abstract}
Celem przeprowadzonych badań było określenie wpływu parametrów skrawania na jakość powierzchni obrobionej podczas toczenia wzdłużnego superstopu Inconel 718 bez udziału cieczy chłodząco-smarującej. Zrealizowane badania posłużyły do określenia częstotliwości powstawania narostu (oblepień) na obrobionej powierzchni podczas obróbki na sucho. Uzyskane wyniki pokazują, że podczas obróbki stopów na osnowie niklu bez udziału cieczy chłodząco-smarującej najkorzystniej jest stosować większe głębokości skrawania i większe wartości posuwu. Podczas przeprowadzonych badań najmniejsze wartości częstotliwości powstawania narostu na powierzchni obrobionej otrzymano przy zastosowaniu najwyższych parametrów skrawania podczas prób, tj. $f=0,21 \mathrm{~mm} / \mathrm{obr}$. i $a_{p}=0,3 \mathrm{~mm}$. Z kolei najwyższe wartości częstotliwości powstawania narostu na powierzchni obrobionej otrzymano podczas skrawania z najmniejszymi parametrami, tj. $f=0,05 \mathrm{~mm} / \mathrm{obr}$. i $a_{p}=0,05 \mathrm{~mm}$. Rezultaty badań pokazują relację minimalnej grubości warstwy skrawanej z wartością promienia zaokrąglenia krawędzi skrawającej. Uwidacznia się to zwłaszcza przy małych przekrojach warstwy skrawanej.
\end{abstract}

Słowa kluczowe: częstotliwość narostu, węgliki spiekane, parametry skrawania

\section{Wprowadzenie}

Żarowytrzymałe stopy (zwane także superstopami) na osnowie niklu, do których należy Inconel 718, są bardzo szeroko stosowane w konstrukcjach silników lotniczych. Stop, który jest tematem niniejszej pracy, należy do najczęściej wykorzystywanych spośród dostępnych na rynku superstopów. Około $45 \%$ odkuwek i 25\% odlewów jest wykonywanych ze stopu Inconel 718 [1]. Właściwość tego materiału, skłonność do reakcji z narzędziem skrawającym, powoduje szybsze zużycie ostrza, a co za tym idzie zmianę jego mikrogeometrii. Części wykonywane $\mathrm{z}$ tego materiału często mają narzucone bardzo rygorystyczne warunki kształtu i chropowatości [5], a zatem odpowiedni dobór narzędzi skrawających oraz parametrów skrawania jest niezwykle istotny w procesie obróbki tych materiałów.

\footnotetext{
1 Autor do korespondencji/corresponding author: Piotr Szablewski, Pratt \& Whitney Kalisz/PWSZ Kalisz, ul. Elektryczna 4a, tel.: 667681866, e-mail: piotr.szablewski@pwk.com.pl

2 Tadeusz Chwalczuk, Politechnika Poznańska, e-mail: tadeusz.chwalczuk@put.poznan.pl
} 
Istotnym aspektem podczas obróbki superstopów jest odpowiedni sposób chłodzenia strefy skrawania, ponieważ generowana jest znaczna ilość ciepła. Jest to związane z małym współczynnikiem przewodności cieplnej tych materiałów $(11,4 \mathrm{~W} / \mathrm{mK})$ [4]. Pusavec i inni [3] badali wpływ ośrodka chłodzącego doprowadzanego do strefy skrawania na zużycie ostrzy skrawających. W swoich badaniach testowali skrawanie na sucho, z minimalnym wydatkiem cieczy chłodząco-smarującej (MQL), chłodzenie kriogeniczne i hybrydę chłodzenia kriogenicznego z MQL. Najlepsze rezultaty uzyskano tą ostatnią metodą chłodzenia, natomiast najgorsze wyniki otrzymano podczas skrawania na sucho.

Jafarian i inni [2] zwracają uwagę, że naprężenia wprowadzane do warstwy wierzchniej podczas skrawania negatywnie wpływają na trwałość części. Należy minimalizować ilość generowanych naprężeń, niestety, zużyte narzędzie wprowadza znacznie większe naprężenia niż nowe ostrze.

\section{Zakres i metodyka badań}

Badania dotyczyły toczenia wzdłużnego wałka materiału Inconel 718 o twardości 35 HRC. W badaniach zastosowano płytki wieloostrzowe WNMG 080408-NEX EH510Z z powłoką TiN/AIN. Próby toczenia przeprowadzono na tokarce uniwersalnej TUR560 w laboratorium Politechniki Poznańskiej. Próby przeprowadzono bez użycia cieczy chłodząco-smarującej. Na podstawie zaleceń producentów i wcześniejszych badań przyjęto następujące parametry skrawania: $v_{c}=63 \mathrm{~m} / \mathrm{min}, f=0,05-0,21 \mathrm{~mm} / \mathrm{obr} ., a_{p}=0,05-0,3 \mathrm{~mm}$.

Do oceny morfologii powierzchni obrobionej zastosowano średnią częstotliwość powstawania resztki na powierzchni obrobionej $f_{n}$, którą określono na podstawie wzoru:

$$
f_{n}=\frac{1}{t}
$$

a czas $t$ wyznaczono z zależności:

$$
t=\frac{60 \cdot L_{n}}{1000 \cdot v_{c}}
$$

gdzie: $L_{n}$ - średnia odległość pomiędzy kolejnymi narostami (rys. 1),

$v_{c}$ - prędkość skrawania.

Ostatecznie

$$
f_{n}=\frac{1000 \cdot v_{c}}{60 \cdot L_{n}}
$$


Odległości $L_{n i}$ zostały zmierzone w dziesięciu losowo wybranych miejscach. Rozproszenie wyników przedstawiono, podając rozstęp. Częstotliwość $f_{n}$ określono dla trzech wartości posuwu $f$ oraz dla stałej wartości dosuwu $a_{p}=0,3 \mathrm{~mm}$ i prędkości skrawania $v_{c}=63 \mathrm{~m} / \mathrm{min}$.

Rys. 1. Schemat metody pomiaru odległości $L_{n i}$ pomiędzy kolejnymi nalepieniami

Fig. 1. Diagram of the method of measuring the distance $L_{n i}$ between accretions

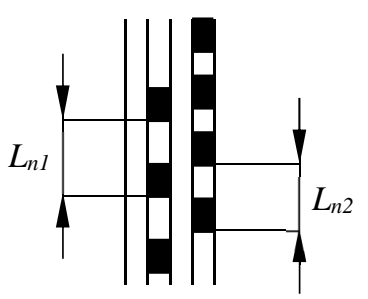

\section{Wyniki badań $\mathrm{i}$ ich analiza}

Podczas przeprowadzonych badań poddano ocenie topografię powierzchni obrobionej w warunkach zróżnicowanych wartości posuwu $f$ i głębokości skrawania $a_{p}$. Na rysunkach 2-4 przedstawiono powierzchnię obrobioną po toczeniu Inconelu 718 (35 HRC) płytką z węglika spiekanego z powłoką EH510Z.

a)

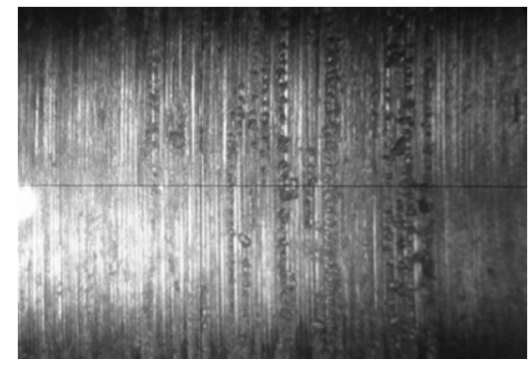

Rys. 2. Widok powierzchni obrobionej po toczeniu Inconelu 718; $a_{p}=0,3 \mathrm{~mm}$, przy różnych wartościach posuwu $f$ : a) 0,05 mm/obr., b) $0,105 \mathrm{~mm} / \mathrm{obr}$, c) $0,21 \mathrm{~mm} / \mathrm{obr}$.

Fig. 2. View of the machined surface after turning Inconel 718; $a_{p}=0,3 \mathrm{~mm}$, and different feed rates $f:$ a) 0.05 $\mathrm{mm} / \mathrm{rev}$, b) $0.105 \mathrm{~mm} / \mathrm{rev}$, c) 0.21 $\mathrm{mm} / \mathrm{rev}$. b)

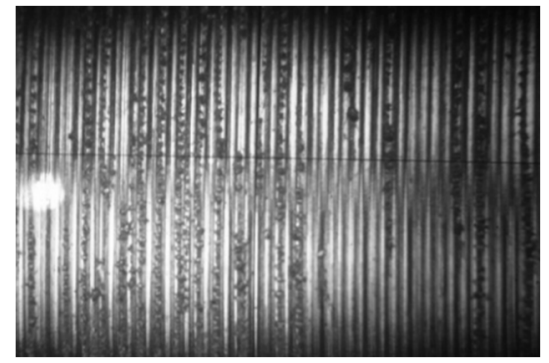

c)

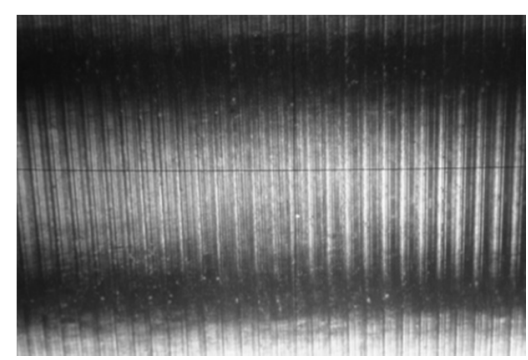

Cechą charakterystyczną dla wszystkich przedstawionych powierzchni jest to, że niezależnie od głębokości skrawania $a_{p}$, dla małych wartości posuwu ( $f=0,05 \mathrm{~mm} / \mathrm{obr}$.) na powierzchni obrobionej występują pozostałości niezeskrawanej warstwy skrawanej. Wraz ze wzrostem posuwu ilość tych pozostałości 
maleje. W zakresie badanych głębokości skrawania $a_{p}$ skłonność do występowania pozostałości niezeskrawanej warstwy zaobserwowano szczególnie wyraźnie dla $a_{p}=0,3 \mathrm{~mm}$. W tabeli 1 przedstawiono wyniki pomiarów odległości $L_{n i}$ pomiędzy kolejnymi oblepieniami na powierzchni obrobionej.

a)

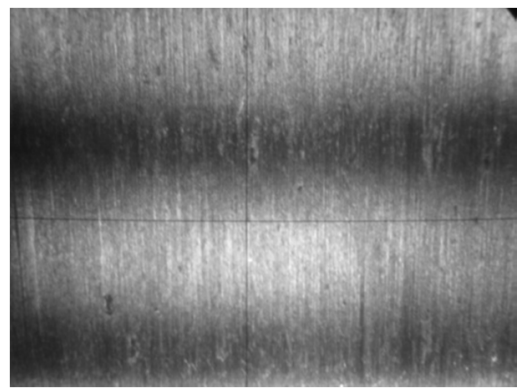

c)

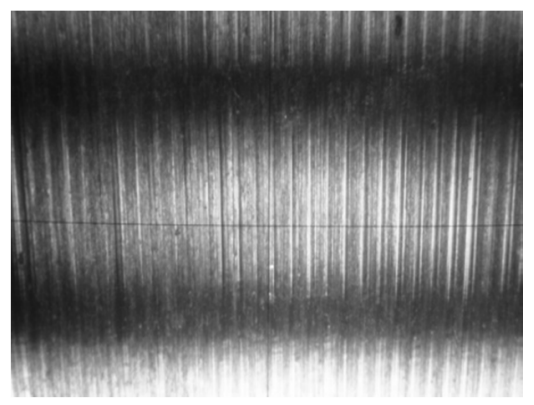

b)

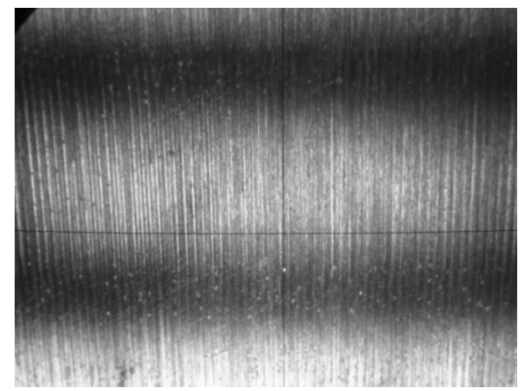

Rys. 3. Widok powierzchni obrobionej po toczeniu Inconelu 718; $a_{p}=0,05 \mathrm{~mm}$, przy różnych wartościach posuwu $f$ : a) 0,05 $\mathrm{mm} / \mathrm{obr}$., b) 0,105 $\mathrm{mm} / \mathrm{obr}$., c) $0,21 \mathrm{~mm} / \mathrm{obr}$.

Fig. 3. View of the machined surface after turning Inconel 718; $a_{p}=0,3 \mathrm{~mm}$, and different feed rates $f$ : a) 0.05 $\mathrm{mm} / \mathrm{rev}$, b) $0.105 \mathrm{~mm} / \mathrm{rev}$, c) 0.21 $\mathrm{mm} / \mathrm{rev}$.

Tabela 1 . Zestawienie wyników pomiaru odległości $L_{n i}$ pomiędzy kolejnymi oblepieniami na powierzchni obrobionej

Table 1. Results of measurement of distance between accretions on machined surface

\begin{tabular}{|c|c|c|c|c|c|c|c|c|c|}
\hline $\begin{array}{c}f \\
{[\mathrm{~mm} / \mathrm{obr} .]}\end{array}$ & \multicolumn{8}{|c|}{$\begin{array}{c}L_{n i} \\
{[\mathrm{~mm}]}\end{array}$} & $\begin{array}{c}\bar{L}_{n} \\
{[\mathrm{~mm}]}\end{array}$ \\
\hline 0,05 & 0,085 & 0,103 & 0,093 & 0,087 & 0,092 & 0,103 & 0,090 & 0,089 & 0,0932 \\
\hline 0,105 & 0,110 & 0,140 & 0,089 & 0,082 & 0,120 & 0,144 & 0,110 & 0,117 & 0,1133 \\
\hline 0,21 & 0,331 & 0,359 & 0,263 & 0,385 & 0,617 & 0,377 & 0,225 & 0,384 & 0,3654 \\
\hline
\end{tabular}

Rysunek 4 przedstawia zależność częstotliwości powstawania pozostałości na powierzchni obrobionej Inconelu 718 po toczeniu dla różnych wartości posuwu $f$. Największą średnią wartość częstotliwości $\bar{f}_{n}$ zanotowano dla posuwu $f=0,05 \mathrm{~mm} /$ obr., a najmniejszą częstotliwość - dla posuwu $f=0,21 \mathrm{~mm} / \mathrm{obr}$. Fakt ten potwierdza, że przy posuwie $f=0,21 \mathrm{~mm} / \mathrm{obr}$. proces jest bardziej stabilny. Na rysunku 5 przedstawiono wybrane wióry otrzymane podczas toczenia 
stopu Inconel 718 z różnymi wartościami posuwu. Zależnie od wartości stosowanego posuwu na jednej krawędzi wióra można zaobserwować ubytki.

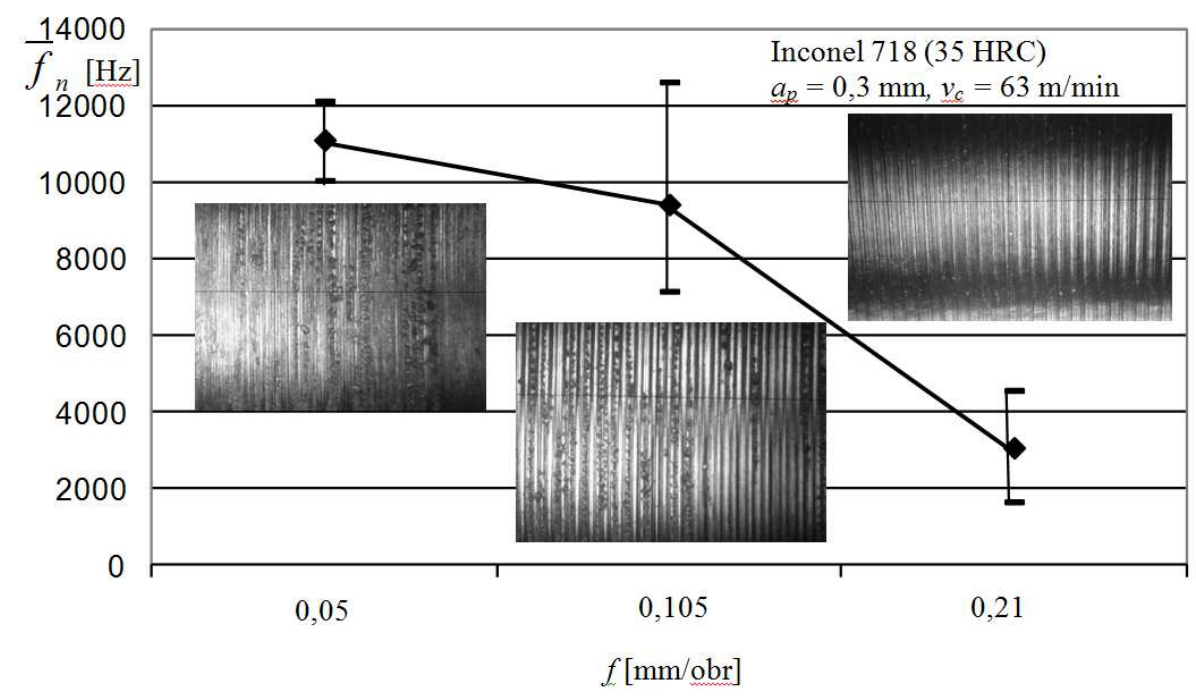

Rys. 4. Wpływ posuwu $f$ na częstotliwość powstawania narostu (oblepień) na powierzchni obrobionej Inconelu 718 podczas toczenia ostrzem z węglików spiekanych

Fig. 4. Influence of feed rate $f$ on the frequency of formation of accretions on machined surface during turning by carbide insert

a)

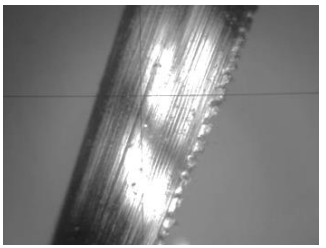

b)

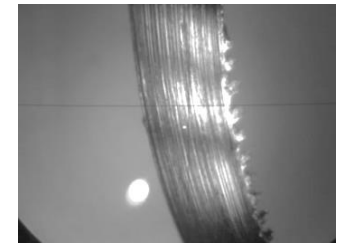

c)

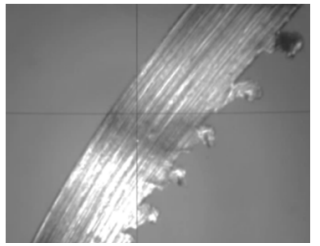

Rys. 5. Wióry po skrawaniu stopu Inconel 718 płytką z węglików spiekanych z powłoką EH510Z; $a_{p}=0,3 \mathrm{~mm}$ : a) $f=0,21 \mathrm{~mm} / \mathrm{obr}$., b) $f=0,10 \mathrm{~mm} / \mathrm{obr}$., c) $f=0,05 \mathrm{~mm} / \mathrm{obr}$.

Fig. 5. Chips after machining of Inconel 718 alloy by carbide insert with coating EH510Z; $a_{p}=0.3 \mathrm{~mm}$ : a) $f=0.21 \mathrm{~mm} / \mathrm{rev}$., b) $f=0.10 \mathrm{~mm} / \mathrm{rev}$., c) $f=0.05 \mathrm{~mm} / \mathrm{rev}$.

\section{Podsumowanie}

Obróbka na sucho stopu Inconel 718 powoduje powstawanie na powierzchni obrobionej oblepień. Przedstawione w artykule materiały pokazują, że wielkość tych oblepień zależy zarówno od głębokości skrawania, jak i od posuwu.

Częstotliwość występowania oblepień na powierzchni obrobionej maleje wraz ze wzrostem posuwu. Podobnie dzieje się z ubytkiem obserwowanym w wiórze. Dla wartości stosowanych posuwów większe ubytki w wiórze 
uzyskano przy posuwie $f=0,05 \mathrm{~mm} / \mathrm{obr}$. Zastosowanie posuwu o wartości $f=0,21 \mathrm{~mm} / \mathrm{obr}$. powoduje mniejsze ubytki w wiórze, ale o większej częstotliwości.

\section{Literatura}

[1] Ahmed N., Mitrofanov A.V., Babitsky V.I., Silberschmidt V.V.: Analysis of material response to ultrasonic vibration loading in turning Inconel 718, Mat. Sci. Eng., A424 (2006) 318-325.

[2] Jafarian F., Amirabadi H., Sadri J.: Experimental measurement and optimization of tensile residual stress in turning process of Inconel 718 superalloy, Measurement, 63 (2015) $1-10$.

[3] Pusavec F., Deshpande A., Yang S., M'Saoubi R., Kopac J., Dillon Jr. O.W., Jawahir I.S.: Sustainable machining of high temperature Nickel alloy - Inconel 718: part 1 predictive performance models, J. Cleaner Production, 81 (2014) 255-269.

[4] Sharman A.R.C., Hughes J.I., Ridgway K.: The effect of tool nose radius on surface integrity and residual stresses when turning Inconel $718^{\mathrm{TM}}$, J. Mat. Proc. Technol., 216 (2015) 123-132.

[5] Szablewski P.: Skrawalność stopu Inconel 718 w procesie toczenia, rozprawa doktorska, Politechnika Poznańska, Poznań 2009.

\section{ASESSMENT OF MORPHOLOGY OF MACHINED SURFACE OF INCONEL 718 ALLOY AFTER LONGITUDINAL TURNING}

\section{S u m m a r y}

The aim of the research was to determine the effect of cutting parameters on the surface quality of Inconel 718 super alloy during longitudinal turning without the use of a lubricant. Completed research was used to determine the frequency of the accretion on the machined surface during dry turning. The results show that during machining of nickel based alloys without using a lubricant, it is preferable to use larger cutting depths and higher feed rates. During the tests, the smallest values of the frequency of accretion on the machined surface were obtained using the highest cutting parameters during the tests, ie. $f=0.21 \mathrm{~mm} / \mathrm{rev}$. and $a_{p}=0.3 \mathrm{~mm}$. Whereas the highest values of the frequency of accretion on the machined surface were obtained during the cutting with the lowest parameters, ie. $f=0.05 \mathrm{~mm} / \mathrm{rev}$. and $a_{p}=0.05 \mathrm{~mm}$.

The results of the study show the relation of the minimum thickness of the cutting layer to the radius on the cutting edge. This is especially visible with small cross-section of the cutting layer.

Keywords: frequency of accretion, sintered carbide, cutting parameters

DOI: $10.7862 / \mathrm{rm} .2017 .34$

Otrzymano/received:12.07.2017

Zaakceptowano/accepted: 27.09.2017 